\title{
Surface resistivity and mechanical properties of rotationally molded polyethylene/graphite composites
}

\author{
Washington Mhike and Walter W. Focke* \\ Institute for Applied Materials, Department of Chemical Engineering, University of Pretoria, Private Bag X20, \\ Hatfield, Pretoria, 0028, South Africa
}

\begin{abstract}
Antistatic polymers are required to safely dissipate static charges from component surfaces. Our overall objective is to develop cost-effective flame retarded and antistatic polyethylene compounds suitable for rotomolding. This communication considered the surface resistivity and mechanical properties of rotationally molded linear low density polyethylene (LLDPE)/graphite composites containing natural Zimbabwean graphite, expandable or expanded graphite. Dry blending and melt compounding were employed to obtain antistatic composites at the lowest graphite contents. Dry blending was found to be an effective mixing method for rotomolding antistatic LLDPE/graphite composites, thereby eliminating an expensive compounding step. Dry blended Zimbabwean graphite composites showed the lowest surface resistivity at all graphite contents, with surface resistivity of $10^{5} \Omega / \square$ at 10 wt.\%. Although rotomolded powders obtained following melt compounding of Zimbabwean graphite exhibited higher resistivity values, the variability was much lower. Injection molding resulted in surface resistivity values above $10^{14} \Omega / \square$ for all compositions used. The rotomolded composites exhibited poor mechanical properties, in contrast to the injection molded composites. The Halpin-Tsai model showed good fits to the tensile modulus data of injection molded Zimbabwean and expandable graphite.
\end{abstract}

\footnotetext{
* Correspondence to: W.W. Focke; e-mail: walter.focke@up.ac.za
} 


\section{INTRODUCTION}

Rotational molding, also referred to as rotomolding or rotocasting, is an attractive technique well-suited for the manufacture of hollow parts with complex shapes [1]. Unlike other polymer forming processes, rotomolded products are nearly stress-free. Short production runs are viable as the molds are relatively inexpensive to fabricate. Operational disadvantages include high operating temperatures and long cycle times [2-4]. The range of polymer resins suitable for rotomolding is limited as few have the thermal stability demanded by the process [5].

Polyethylene is the principal rotomolding material [6]. The paucity (and limited mobility) of charge carriers [7] results in a high volume resistivity that makes polyethylene an effective insulator. The high surface resistivity allows the buildup and retention of static charges on product surfaces. Static electricity poses a nuisance as well as a hazard as it is a potential ignition source for fires and explosions.

Electrostatic dissipative materials have electrical conductivities sufficient to facilitate safe dissipation of static charges [7]. The term 'antistatic' is commonly applied to describe such materials [8]. IEC standard 61340-5-1 classifies materials with a surface resistivity between $10^{5} \Omega / \square$ and $10^{11} \Omega / \square$ as antistatic. Materials with surface resistivity values above and below this range are regarded as insulating and conductive respectively.

Polymers can be rendered electrostatic dissipative in several ways [9] but studies specific to rotomolding applications are rare [10-12]. Antistatic agents, intrinsically conductive polymers (ICPs), inherently dissipative polymers (IDPs) and conductive particulates are commonly used [9]. Conventional antistatic agents offer limited static protection due to their migratory nature and the need for a minimum relative humidity [9]. Their high volatility further limits their use in the rotomolding process [13]. Inherently dissipative polymers (IDPs) and intrinsically conductive polymers (ICPs) are also not suitable 
owing to insufficient thermal stability [14]. However, conductive particulate fillers such as graphite are an attractive option for rotomolding.

Natural flake graphite (FG) is a layered mineral comprising stacked graphene sheets of covalently bonded carbon atoms. It has a high electrical conductivity suitable even for electrochemical applications [15]. The conductivity of the flakes is anisotropic. It is high in the in-plane direction but much lower in the direction perpendicular to the graphene layers [16].

Expandable graphite (EG) is made by partial oxidation of the graphene sheets with simultaneous intercalation (i.e., insertion) of charge neutralizing guest species (e.g., sulfuric acid anions) in-between the stacked graphene layers [17]. Upon exposure to high temperatures, the intercalated guest ions decompose forming a gas that causes the flakes to expand rapidly in a worm-like manner and to occupying a much larger volume $[15,16]$. Expandable graphite is a good intumescent flame retardant for polyethylene [18] at a loading of 10 wt.\% and above. Expandable graphite has similar in-plane electrical conductivity as natural flake graphite [19]. This means that it could impart both antistatic and flame retardant properties to polyethylene.

Consider a polymer composite based on an insulating matrix filled with conductive particles. The variation of the electrical resistivity with filler loading follows a universal trend $[9,20-22]$. At low filler loadings the conductive particles are well separated by the polymer matrix and do not make contact with each other. In this composition range the resistivity barely decreases with filler loading. Above critical filler loading there is enough of the filler present so that a three-dimensional conductive network of touching conducting particles forms. This is the so-called percolation threshold and the resistivity decreases abruptly by several orders of magnitude. Beyond the percolation threshold the resistivity decrease levels off and adding more of the conductive filler makes little difference. 
Apart from the effect of filler loading, the resistivity of graphite/thermoplastic composites also depends on the type of graphite, the particle size and shape (in particular the aspect ratio); the nature of the polymer matrix (especially the degree of crystallinity), and the processing technique employed [23-29]. The filler particle aspect ratio is chiefly important. High aspect ratio fillers establish conductive networks at lower dosage levels. Hence the recent interest in expanded graphite and graphite nanoplatelets, as they promise attainment of resistivity at low percolation thresholds $[17,26,29,30,31]$. However, agglomeration and segregation of particulate fillers is a potential problem in rotomolding [1, 32-34].

Rotomolding filled polyethylene composites can be done in two different ways. The filler and neat polymer powders can simply be dry-blended before use. Alternatively, the filler can first be dispersed in the polymer matrix by melt compounding. The resulting composite is then pulverized before use.

Our overall aim is to develop cost-effective flame retarded and antistatic polyethylene compounds suitable for rotomolding. The objectives of this particular investigation were to compare the utility of different graphite forms to reduce surface resistivity and to establish whether melt compounding of graphite filler is essential in this regard. In pursuit of these goals, the surface resistivity and the mechanical properties of rotomolded graphite/polyethylene composites were determined. Composites were prepared using dry blending of the filler and neat polymer powders and also by powders obtained by the milling of pre-compounded material. Natural Zimbabwean flake graphite, expandable graphite and pre-expanded graphite were explored as fillers. The properties of the composites prepared via these rotomolded routes were compared to injection molded samples. 


\section{EXPERIMENTAL}

\section{Materials}

The linear low density polyethylene (LLDPE) was supplied by Sasol Polymers. It was a hexene comonomer-based rotomolding powder (Grade HR 411: MFI $3.5\left(190^{\circ} \mathrm{C} / 2.16\right.$ $\mathrm{kg}$ ); density $0.939 \mathrm{~g} / \mathrm{cm}^{3}$; particle size: $\left.90 \%<600 \mu \mathrm{m}\right)$. Natural Zimbabwean flake graphite (FG) was obtained from BEP Bestobell, Johannesburg. Chemserve Systems supplied the release agent Sliprolease $20 \mathrm{~K}$ and Orchem provided the antioxidant Orox PK (polymerized 2,2,4-trimethyl-1,2-dihydroquinoline). Two grades of expandable graphite ES 250 B5 (onset temperature $220^{\circ} \mathrm{C}$ ) and ES170 300A (onset temperature $300^{\circ} \mathrm{C}$ ) were supplied by Qingdao Kropfmuehl Graphite (China). The latter constituted the expandable form used in this study. The former could not be used for rotomolding as the expansion onset temperature was too low. Instead it was used to prepare the pre-expanded graphite (PEG) form. This was done by exposing ES250 B5 grade powder to high heat for 5 minutes by placing it in a Thermopower electric furnace set at $600^{\circ} \mathrm{C}$. The properties of the various graphite grades are reported in Table 1.

The graphite particle size distributions were determined with a MastersizerHydrosizer 2000 (Malvern Instruments, Malvern, UK). The specific surface areas of the graphite powders were determined with a Nova 1000 e BET in $\mathrm{N}_{2}$ at $77 \mathrm{~K}$. Densities were determined on a Micrometrics AccuPyc II 1340 helium gas pycnometer.

LLDPE and graphite morphologies were studied using a JEOL JSM 5800LV scanning electron microscope (SEM) (for low resolution micrographs) and a Zeiss Ultra FESEM (for high resolution micrographs). The acceleration voltages used in these instruments were $20 \mathrm{kV}$ and $1 \mathrm{kV}$ respectively. No electro-conductive coating was applied on the graphite particles. 
The elemental composition of the graphite powders was determined by XRF analysis performed using the ARL 9400XP+ XRF spectrometer. The samples were prepared as pressed powder briquettes and introduced to the spectrometer.

\section{Methods}

A stainless steel rectangular cuboid mold with inside dimensions $200 \mathrm{~mm}$ x $150 \mathrm{~mm}$ x $100 \mathrm{~mm}$ was used for rotomolding. A constant volume of material $\left(320 \mathrm{~cm}^{3}\right)$ was used for all compositions in order to obtain a constant part thickness. The charge mass was adjusted considering the density of the various components. The rotomolding machine was a modified Thermopower convection oven that was fitted with a biaxial mold rotating mechanism.

Dry blended samples. Composites containing 5, 10, 15 and 20 wt.\% Zimbabwean graphite, ES 170 300A and expanded ES250 B5 were prepared. The dry blended samples were prepared by blending the LLDPE, graphite and heat stabilizer Orox PK for one minute using a coffee blender. The rotomolding processing conditions are stated in Table 2 . The mold was cooled in the oven using ambient air.

Compounded samples. LLDPE composites with 5, 10, 15, 20 wt.\% graphite were prepared with Zimbabwean graphite and ES170 300A, with an additional 25 wt.\% graphite composition for the Zimbabwean graphite. LLDPE/pre-expanded graphite ES250 B5 samples contained 2, 5, 8 or 10 wt.\% filler. LLDPE composites with the Zimbabwean graphite and ES170 300A were manually mixed before compounding. The pre-expanded ES250 B5 was mixed with LLDPE in a Jones vertical high speed mixer for two minutes before compounding.

All the samples were melt-compounded in a $40 \mathrm{~mm}$ co-rotating Berstorff twin screw extruder using the processing conditions given in Table 2. The composite strands were water cooled, air dried and granulated into pellets. These were then milled into rotomolding powder 
using a Pallmann 300 pulverizer. The heat stabilizer Orox PK was blended into the powder using a coffee blender for a period of one minute. The rotomolding conditions are reported in Table 2. The mold was allowed to cool down inside the oven using ambient air.

Injection molding. The various test specimens indicated in Table 2 were injection molded on an Engel EC088 injection molding machine using the compounded samples.

\section{Characterization}

Surface resistivity Surface resistivity was determined according to IEC 61340-2-3 using a Vermason TB-7549 concentric ring probe and high resistance test kit. The surface resistivity tests were performed on the exterior surfaces of $120 \mathrm{~mm}$ x $80 \mathrm{~mm}$ sheets cut out from the rotomolded specimens. The surface resistivity of injection molded samples were determined using $60 \mathrm{~mm} \phi$ circular discs molded for ASTM drop impact tests. All tests were performed on as-molded samples placed on an insulating wooden surface at ambient conditions. Each reported value represents the geometric mean of five separate measurements done on different samples. The error bars reported in the Figures span the full range of values measured for each sample set.

Graphite distribution in the composites and composite morphology. Polished crosssections of the composites were prepared to study the distribution of the graphite fillers. Sectioned samples pieces were first cast in an epoxy resin (Specifix 20). After the resin had set, they were polished on a Buehler Alpha 2 speed grinder-polisher. These specimens were viewed with a Zeiss Imager fitted to an A1m optical microscope under the epi-polarized light mode.

The morphology of the composites was also observed with scanning electron microscopy (SEM). Samples were fractured in liquid nitrogen and coated with gold in an 
Emitech K550 X coating machine. The fracture surfaces were viewed using an acceleration voltage of $5 \mathrm{kV}$ in a JEOL JSM 5800LV machine.

Tensile properties. Tensile tests according to ASTM D 638-08 were performed at 23 ${ }^{\circ} \mathrm{C}$ on a Lloyds Instruments LRX Plus machine fitted with a $5 \mathrm{kN}$ load cell using an extension rate of $50 \mathrm{~mm} / \mathrm{min}$. Dumbbells with a gauge length of $35.5 \mathrm{~mm}$ were punched out of sheets cut from the rotomolded samples. Injection molded tensile strength specimens (gauge length $35 \mathrm{~mm}$ ) were molded directly. Five specimens were tested for each sample.

Impact testing. The falling weight (Gardner Impact) test was used to determine the impact energy according to ASTM D 5420-04. Square discs (42 mm x $42 \mathrm{~mm}$ ) were cut from the rotomolded samples. The average thickness of the square discs was $2.88 \pm 0.39 \mathrm{~mm}$. Circular discs (diameter $60 \mathrm{~mm}, 3 \mathrm{~mm}$ thick) were injection molded directly. The mass of the drop weight used was $0.9 \mathrm{~kg}$. For each sample, the expected break height was first determined, and then 20 specimens were used for the actual tests. The tests were carried out at room temperature conditions.

Rheology. Viscosity determinations for compounded samples containing $10 \mathrm{wt} . \%$ graphite were done on an Anton Paar Physica MCR301 rheometer. Estimates of the zero shear viscosity were obtained by operating the machine at a shear rate of $0.01 \mathrm{~s}^{-1}$. A parallel plate measuring system ( $1 \mathrm{~mm}$ gap and $50 \mathrm{~mm} \phi)$ fitted with a Peltier heating system (Anton Paar PTD200 attachment) was used. The tests were done at the temperatures ranging from $140-200^{\circ} \mathrm{C}$

\section{RESULTS}

\section{Graphite particle characteristics}

Figure 1 shows the particle size distribution of the various graphite types used. The $\mathrm{d}_{50}$ particle size of the Zimbabwean flake graphite was about four times lower than that of the 
two expandable graphite grades. The $\mathrm{d}_{50}$ particle size, BET surface area, and densities of the different graphites are presented in Table 1. The surface area of the expandable graphite increased almost sevenfold when it expanded on heat treatment at $600^{\circ} \mathrm{C}$. Figure 2 shows the flake-like nature of the natural and expandable graphites. The expanded graphite in Figure 2 has a worm-shaped, accordion-like structure. Slit-shaped gaps between the graphite platelets are clearly visible.

XRF results revealed that the carbon content of the Zimbabwean flake graphite was about 92 wt.\%. The main impurities appeared to be silica and clay minerals. The carbon content of both the two expandable graphite samples were $90 \mathrm{wt} . \%$ and $88 \mathrm{wt} . \%$ for ES 250 B5 and ES170 300A respectively.

\section{Surface resistivity}

The surface resistivity of LLDPE and all injection molded graphite composites featured surface resistivity values exceeding $10^{14} \Omega / \square$. Figures 3 to 5 show the exterior surface resistivity values measured for the rotomolded LLDPE/graphite composites made by the two processing methods and containing different graphite types. The resistivity of the composites showed the expected decrease in surface resistivity with increasing graphite content [9]. Dry blend-prepared flake graphite-based composites had lower resistivity values than those based on powders obtained from compounded samples (See Figure 3). At 10 wt.\% graphite loading, the surface resistivity was $10^{5} \Omega / \square$, equal to the upper limit of the conductive range. This was almost two orders of magnitude lower than the corresponding value for the melt compounded composite. However, the resistivity values for compounded composites showed significantly less variability. The dry blend and melt compounded composites reached the IEC 61340-5-1 static dissipative rating at 5 and $10 \mathrm{wt} . \%$. 
Dry blend expandable graphite composites exhibited higher resistivity values and only achieved the static dissipative ranking above $20 \mathrm{wt} . \%$ filler (Figure 4). Compounded samples containing $10 \mathrm{wt} . \%$ or more graphite were rated static dissipative. The dry blend expanded graphite-based composites also exhibited lower resistivity values than the corresponding compounded samples (Figure 5). They were more conductive than the composites based on expandable graphite and achieved the static dissipative rating at 8 and 10 wt.\% graphite respectively.

\section{Rheology}

Figure 6 shows the variation of the zero shear viscosity (evaluated at a shear rate of $0.01 \mathrm{~s}^{-1}$ ) with temperature for LLDPE and $10 \mathrm{wt} . \%$ graphite composites. The inclusion of graphite in the polyethylene matrix resulted in a significantly higher melt viscosity; almost double that of the neat LLDPE. Spence \& Crawford [35] showed that rotomolding polymers with relatively higher viscosities resulted in more bubbles. In the range from $140^{\circ} \mathrm{C}$ to $200^{\circ} \mathrm{C}$ the melt viscosity decreased according to the Arrhenius relationship.

$$
\eta=\eta_{o} e^{E / R T}
$$

Where $\eta$ is the zero shear viscosity; $\eta_{\mathrm{o}}$ is the pre-exponential constant with dimensions of viscosity; $E$ is the activation energy; $R$ is the gas constant and $T$ is the absolute temperature. The activation energy was the same for the resin and the compounds and equal to $26.5 \pm 0.3$ $\mathrm{kJ} \cdot \mathrm{mol}^{-1} \cdot \mathrm{K}^{-1}$

\section{Mechanical properties}

Young's modulus. The Young's moduli of the rotomolded and injection molded composites are listed in Table 3. The rotomolded Zimbabwean graphite composites showed modest improvements in the Young's moduli up to $10 \mathrm{wt} \%$ graphite content. Previous 
investigations on the moduli of rotomolded composites also showed an initial improvement, then deterioration thereafter $[1,32,36]$. The expandable and expanded graphite composites did not show a marked improvement in the modulus. Improvements of $23 \%, 20 \%$ and $36 \%$ were observed in the moduli of the injection molded Zimbabwean, expandable and expanded graphite composites respectively at $10 \mathrm{wt} . \%$ loading.

Tensile strength. The tensile yield strength of all the rotomolded graphite composites deteriorated with increase in graphite content (Table 4). However, it is worth noting that the decrease in strength was only $24 \%$ for the dry blend Zimbabwean flake graphite containing 5 wt.\% graphite. At this graphite content, the dry blend composite was static dissipative. This could be an acceptable decrease in strength for some applications. A modest improvement was observed in the tensile strength of all the injection molded composites. The improvement in the injection molded samples was more pronounced in the Zimbabwean flake graphite composites, with a $26 \%$ improvement at 20 wt. \% graphite content.

Elongation-at-break (Table 5). The neat rotomolded LLDPE exhibited a high elongation-at-break of $1044 \%$, compared to that of the neat injection molded LLDPE which was $441 \%$. The elongation-at-break for the injection molded composites initially improved with graphite content, before it deteriorated. Modest improvements of up to $12 \%$ (5 wt.\% Zimbabwean graphite), 8\% (5 wt.\% Expandable graphite) and 10\% (2 wt.\% Expanded graphite) were observed. The elongation-at-break for all the rotomolded composites decreased dramatically with an increase in graphite content.

Impact strength. The Gardner Impact falling-weight impact strength of the rotomolded composites decreased drastically with increase in graphite content (Table 6). A more gradual decrease in the impact strength was observed for the injection molded composites. The rotomolded samples exhibited a brittle failure mode; they showed radial cracks from the impact point. In contrast, the injection molded samples showed ductile 
failures. Previous studies also found a decrease in the impact strength of graphite polyethylene composites $[37,38]$.

\section{DISCUSSION}

The variability of the resistivity data is very low for melt compounded Zimbabwean flake graphite composites and high for the dry blend composites (Figure 3). However, better conductivity performance was achieved with dry blending. It seems that the filler particles were more homogeneously dispersed and distributed in the compounded composites compared to the dry blended composites (Figure 7 and Figure 9). Good dispersion does not necessarily promote the formation of conductive pathways. The graphite flakes in dry blended composites appear to feature randomly oriented and interconnected clusters (Figure 7 and Figure 9) that are more conducive for the formation of conductive pathways. Dry blending did not have the same effect on expandable graphite (Figure 7). In contrast, the compounded expandable graphite composites showed a more random orientation of the graphite flakes. The flake size appears to have been reduced significantly. A decrease in graphite flake size was also observed in the flake and expanded graphite composites (Figure 7). A previous study showed that the percolation threshold decreases with a reduction in graphite platelet size [23].

The higher surface resistivity of the injection molded samples can be explained by the good dispersion of all the types of graphite in the polymer matrix, which does not promote the formation of conductive paths (Figure 8). Another observation was the tendency for the graphite platelets to be partially oriented in the direction of melt flow (Figure 8). Apparently some expanded graphite platelets were damaged or crumpled by the high-shear melt processing. 
Polymer reinforcement depends on effective stress transfer from the matrix to the filler. Strong matrix-filler interaction is a prerequisite for effective stress transfer [39]. Rotomolding is a pressure and shear-free process. In comparison, injection molding involves pressure and high shear mixing that facilitates wetting and dispersion of the graphite fillers in injection molding, hence the better improvement in the moduli and strength. The difference in polarity between graphite and polyethylene results in poor filler-matrix interfacial adhesion. Also, loose expanded graphite platelet stacks are visible, with the expanded graphite squashed and folded, but not exfoliated (Figure 9). This weakens the composites.

Cavities in wall cross-sections, graphite agglomerates and surface flaws (including pinholes) (Figures 7 and 9) all deteriorate mechanical properties. Voids do not carry any load [40]. The injection molded composites were void free (Figure 8), hence the better modulus and strength values.

The rotomolded graphite composites showed a higher incidence of cavities and surface flaws. Resins with low zero-shear viscosities sinter easily and their flowability enables the filling of intricate mold details and good surface finishes [41]. The flake-like nature and random dispersion of the graphite particles makes it more difficult for gas bubbles to escape. The higher apparent melt viscosity of the composites (Figure 6) makes degassing even more difficult. Spence \& Crawford [35] observed that for bubbles to travel out of the polymer melt, the viscosity should be less than 3-4 kPa.s. From Figure 6, it is evident that melt temperatures beyond $200^{\circ} \mathrm{C}$ would be necessary for this to occur. Trapped air bubbles can be detrimental to the mechanical properties due to thermo-oxidative degradation.

Surface flaws [42] and particle clusters [43] are stress concentration points that weaken the composites. Particle clusters are noticeable (Figures $7 \& 9$ ), particularly in the composites that are conductive. The rotomolded compounded samples were expected to 
perform much better due to better dispersion and wetting, compared to the dry blended composites, but they also had voids and pinholes.

In the injection molded composites (Figure 8), the graphite filler particles appeared partially aligned in the direction of the melt flow (horizontal direction in the photomicrographs). As this was the direction of tensile testing, it provided better reinforcement. Preferred orientations were not apparent in the rotomolded composites.

A reduction in the elongation-at-break as observed for the rotomolded composites is usually observed for filled polymers. The particles act as stress concentration points that initiate crack propagation [24]. It has been previously suggested that if the interaction between graphite platelets and polyethylene was stronger than that between graphite nanoplatelets, then the elongation at break could improve as a result of oriented graphite platelets sliding over each other [44]. This explanation is suggested for the initial improvement in the elongation of injection molded composites.

Rigid fillers decrease the impact strength of filled polymers due to differences in stiffness [37]. However, the rapid deterioration of the impact strength and the mode of failure of rotomolded composites compared to the injection molded composites suggest poor adhesion between the graphite filler particles and the polymer matrix. The surface flaws observed in the composites decreased the impact strength. Particle clusters [45] and poor dispersion also contributed to a decrease in impact strength [46].

\section{Modeling the Young's modulus}

The Halpin-Tsai equation [47] is widely used to predict the modulus of composites $[48,49]$. The equation has the form of

$\frac{E}{E_{p}}=\frac{\left(1+\xi \eta V_{f}\right)}{\left(1-\eta V_{f}\right)}$ 
where $E$ is the composite tensile modulus in the longitudinal or transverse direction with respect to the alignment of particles, $E_{p}$ is the tensile modulus of the matrix, $V_{f}$ is the volume fraction filler and $\xi$ is a shape factor that depends on the geometry of the filler particles and their relative orientation with respect to the load direction. The parameter $\eta$ is given by

$\eta=\frac{\left(E_{f} / E_{p}-1\right)}{\left(E_{f} / E_{p}+\xi\right)}$

where $E_{f}$ is the tensile modulus of the filler. Van Es [50] proposed corrected shape factors for platelet reinforcements for the longitudinal $\left(E_{C L}\right)$ and transverse $\left(E_{C T}\right)$ composite modulus as $\xi_{L}=\frac{2}{3} \frac{w}{t}$ and $\xi_{T}=2$ respectively. Van Es [50] also approximated the composite modulus of a matrix containing randomly oriented platelets using an averaging scheme as follows:

$E_{c}=0.49 E_{C L}+0.51 E_{C T}$

where $E_{c}$ is the composite modulus, $E_{C L}$ and $E_{C T}$ are evaluated from the Halpin-Tsai equations using the respective shape factors $\xi_{L}$ and $\xi_{T}$.

Figure 10 shows least square fits of the Halpin-Tsai equations for the platelets to Young's modulus data of injection molded composites. Perfect platelet alignment in the longitudinal direction and random platelet orientation was considered. The tensile modulus for the graphite was taken as the in-plane value of $1 \mathrm{TPa}$ for the longitudinal modulus, and the c-axis value of $36.5 \mathrm{GPa}$ for the transverse modulus [51]. The tensile moduli of the LLDPE were taken as the measured values listed in Table 3. By assuming perfect alignment and using Equation 1 for the longitudinal modulus, good fits were obtained using $\xi_{L}=5.1$ and $\xi_{L}=3.73$ for Zimbabwean flake graphite and expandable graphite respectively. By considering random orientation of the platelets and using Equation 3 with $\xi_{T}$ fixed at $\xi_{T}=2$, good fits were obtained using $\xi_{L}=8.39$ and $\xi_{L}=5.58$, for Zimbabwean flake graphite and expandable graphite respectively. The fits for perfect platelet alignment and random platelet 
orientation lie on the same lines (Figure 10). These results provide an indication of the residual aspect ratios of the platelets. For perfect alignment of the platelets the aspect ratios were calculated to be 7.7 and 5.6 for the Zimbabwean flake graphite and expandable graphite respectively. For random orientation of the platelets, the aspect ratios were calculated to be 12.6 and 8.4, for the Zimbabwean flake graphite and expandable graphite respectively. The values of the shape factors confirm the anisotropic nature of the graphite flakes. The HalpinTsai model could not be applied to the tensile moduli data for the rotomolded composites because they deteriorated with graphite content.

\section{CONCLUSIONS}

The surface resistivity and mechanical properties of rotationally molded LLDPE/graphite composites using natural Zimbabwean graphite, expandable and preexpanded graphite were investigated. Different processing methods were employed in an attempt to obtain antistatic rotomoldable composites. Dry blending was an effective mixing method for the preparation of rotomolded antistatic LLDPE/Zimbabwean flake graphite composites. The antistatic ranking was reached at just $5 \mathrm{wt} \%$ graphite. At this addition level the Young's modulus of the composite was similar to that of the neat polymer and the tensile strength was $24 \%$ lower. However, elongation-at-break and Gardner impact strength were severely compromised. Rotomolded samples based on pre-compounded Zimbabwean flake graphite at the $10 \mathrm{wt} . \%$ level were also rated antistatic. In this case the modulus was slightly higher and the tensile strength was $29 \%$ lower. The deterioration in the other two mechanical properties was just as severe.

The expandable graphite composites are of particular interest as good fire retardant properties can be achieved at loadings upward of $10 \mathrm{wt} . \%$. At these levels the rotomolded 
samples based on pre-compounded powders are also antistatic. Unfortunately these composites show similarly poor elongation-at-break and Gardner impact values.

The dry blend expanded graphite-based composites also exhibited lower resistivity values than the corresponding compounded samples, similar to the natural flake graphite. They were more conductive than the composites based on expandable graphite and achieved the static dissipative rating at 8 and $10 \mathrm{wt} \%$ graphite respectively. However, they also exhibited poor mechanical properties.

Injection molded versions of all these compositions featured acceptable mechanical properties, but they were not antistatic. The Halpin-Tsai model provided good fits to the experimental tensile modulus data of injection molded Zimbabwean and expandable graphite.

\section{Acknowledgements}

Financial support for this research, from the Institutional Research Development Programme (IRDP) of the National Research Foundation of South Africa and Xyris Technology CC is gratefully acknowledged.

\section{REFERENCES}

1. W. Yan, R.J.T. Tin and D. Bhattacharyya, Compos. Sci. Technol., 66, 2080 (2006).

2. B.I. Chaudhary, E. Takács and J. Vlachopoulos, Polym. Eng. Sci., 41, 1731 (2001).

3. E. Planes, J. Duchet, A. Maazouz and J. Gerard, Polym. Eng. Sci., 48, 723 (2008).

4. M.Z. Abdullah, S. Bickerton, D. Bhattacharyya, R.J. Crawford and E. Harkin-Jones, Polym. Eng. Sci., 49, 1846 (2009).

5. G.L. Beall, Rotational Molding; Design, Materials, Tooling, and Processing, Hanser, Munich (1998).

6. S. Liu and K Peng, Polym. Eng. Sci., 50, 1457 (2010). 
7. L. Jian, L. Ning, S. Yang, J. Wang, and M. Hua, Polym. Compos., 31, 1369 (2010).

8. T. Grasso, G. Gutman and D.M.Yenni, Proceedings Nepcon West Conference, Anaheim, CA, 1985, (1985).

9. R.B. Rosner, IEEE Trans. Device Mater. Reliab., 1, 9 (2001).

10. R. Patch, U.S. Patent, 6,283,320 B1, (2001).

11. G.L. Kelly III and K E. Jones, U.S. Patent, 2002/0108358 A1, (2002).

12. D.F. Angelico, U.S. Patent, US 7992593 B2, (2011).

13. S.J. Dahman, Electrical Overstress/Electrostatic Discharge Symposium, (2003).

14. R.W. Campbell and W. Tan, Electrical Overstress/Electrostatic Discharge Symposium Proceedings, 95 (1995).

15. M. Wissler, J. Power Sources, 156, 142 (2006).

16. D.D.L. Chung, J. Mater. Sci., 37, 1475 (2002).

17. G. Chen, C. Wu, W. Weng, D. Wu, and W. Yan, Polymer, 44, 1781 (2003).

18. R. Xie, and B. Qu, Polym. Degrad. Stab., 71, 395 (2001).

19. W. Zheng, X. Lu and S. Wong, J. Appl. Polym. Sci., 91, 2781(2003).

20. F. Lux, J. Mater. Sci., 28, 285 (1993).

21. R. Struèmpler, and J. Glatz-Reichenbach, J. Electroceram, 3, 329 (1999).

22. M.I. Clingerman, J.A. King, K.H. Schulz and J.D. Meyers, J. Appl. Polym. Sci., 83, 1341 (2000).

23. K. Nagata, H. Iwabuki and H. Nigo, Compos. Interfaces, 6, 483 (1999).

24. I.Krupa and I. Chodak, Eur. Polym. J., 37, 2159 (2001).

25. I. Krupa, I. Novák and I. Chodák, Synth. Met., 145, 245 (2004).

26. G. Chen, X Chen, H. Wang and D. Wu, J. Appl. Polym. Sci, 103, 3470 (2007).

27. V. Panwar and R.M. Mehra, Polym. Eng. Sci., 2178 (2008).

28. S. Bhattacharya, R.P. Tandon, and V.K. Sachdev, J. Mater. Sci., 44, 2430 (2009). 
29. K. Kalaitzidou, H. Fukushima, and L.T. Drzal, Materials, 3,1089 (2010).

30. X. Chen, J. Shen and W. Huang, J. Mater. Sci. Lett., 21, 213 (2002).

31. J. Shen, W. Huang, S Zuo, and J. Hou, J. Appl. Polym. Sci., 97, 51 (2005).

32. B.G. Wesley, ANTEC 1999 Plastics: Bridging the Millennia, Volume 1: Processing, New York City, May 2-6, (1999).

33. D. Martin, P. Halley, R. Truss, M. Murphy, O. Jackson, and O. Kwon, Polym. Int., 52, $1774(2003)$.

34. X. Yuan, A.J. Easteal, and D. Bhattacharyya, J. Mater. Sci., 43, 6057 (2008).

35. A.G. Spence and R.J. Crawford, Polym. Eng. Sci., 36, 993 (1996).

36. A. Robert, and R.J. Crawford, ANTEC 1999 Plastics: Bridging the Millennia, Volume 1: Processing, New York City, May 2-6, (1999).

37. Q. Wang, J. Gao, R. Wang and Z. Hua, Polym. Compos., 22, 97 (2001).

38. Y. She, G. Chen and D. Wu, Polym. Int., 56, 679 (2007).

39. S. Fu, X. Feng, B. Lauke and Y. Mai, Composites Part B, 39, 933 (2008).

40. C.J.R. Verbeek and W.W. Focke, Composites Part A, 33, 1697 (2003).

41. M. Kontopoulou and J. Vlachopoulos, Polym. Eng. Sci., 39, 1189 (1999).

42. R.J. Young and P.A. Lovell, Introduction to Polymers, CRC Press, New York, (1991).

43. A. Yasmin and I.M. Daniel, Polymer, 45, 8211 (2004).

44. L .Wang and G. Chen, J. Appl. Polym. Sci., 116, 2029 (2010).

45. C. DeArmitt and M. Hancock, in Particulate-Filled Polymer Composites, edited by Rothon, R.N., Rapra Technology Limited Shawbury, Shrewsbury, UK, (2003), p377.

46. G. Chen, D. Wu, W. Weng, B. He and W. Yan, Polym. Int., 50, 980 (2001).

47. J.C. Halpin and J.L. Kardos, Polym. Eng. Sci., 16, 344 (1976).

48. C.L. Tucker III and E. Liang, Compos. Sci. Technol., 59, 655 (1999).

49. T.D. Fornes and D.R. Paul, Polymer, 44, 4994 (2003). 
50. M.A. van Es, Polymer-Clay Nanocomposites, the Importance of Particle Dimensions, PhD thesis, Delft University of Technology: Delft, The Netherlands, (2001).

51. H.O. Pierson, Handbook of Carbon, Graphite, Diamond and Fullerenes: Properties, Processing and Applications, Noyes Publications, New Jersey, U.S.A (1993).

\section{LIST OF TABLES}

Table 1. Physical properties of graphite

Table 2. Processing conditions

Table 3. Effect of graphite type and content as well as processing method on the Young's modulus (MPa) of LLDPE /graphite composites

Table 4. Effect of graphite type and content as well as processing method on the Tensile strength (MPa) of LLDPE / graphite composites

Table 5. Effect of graphite type and content as well as processing method on the Elongation-at-break (\%) of LLDPE /graphite composites

Table 6. Drop weight (Gardner) Impact Strength of LLDPE/graphite composites

\section{Figure Captions}

Figure 1. Graphite particle size distributions.

Figure 2. SEM micrographs of polyethylene and graphites: (a) LLDPE; (b) Zimbabwean flake graphite; (c) Expandable graphite ES170 300A; (d) Expandable graphite ES250 B5; (e) Expanded graphite ES250 B5 at low resolution, and (f) at high resolution.

Figure 3. Exterior surface resistivity of rotomolded LLDPE/Zimbabwean flake graphite composites. 
Figure 4. Exterior surface resistivity of rotomolded LLDPE/expandable graphite composites.

Figure 5. Exterior surface resistivity of rotomolded LLDPE/expanded graphite composites.

Figure 6. Zero shear viscosity of compounded LLDPE/graphite composites estimated from the viscosity measured at a shear rate of $0.01 \mathrm{~s}^{-1}$. The graphite content of all the composites was $10 \mathrm{wt} . \%$.

Figure 7. Photomicrographs of polished rotomolded composite sections (5X magnification): Zimbabwean graphite at 15 wt.\% (a) dry blended, and (b) precompounded; expandable graphite at 15 wt.\% (c) dry blended, and (d) precompounded; pre-expanded graphite at $10 \mathrm{wt} \%$ (e) pre-compounded, and (f) dry blended. The exterior wall is on the left hand side.

Figure 8. Photomicrographs of polished injection molded composite sections (5X magnification) containing 10 wt.\% graphite: (a) Zimbabwean flake graphite; (b) expandable graphite, and (c) Pre-expanded graphite.

Figure 9. SEM fractographs of rotomolded composites with 10 wt.\% graphite: Zimbabwean flake graphite (a) dry blended, and (b) pre-compounded; expandable graphite (c) dry blend, and (d) pre-compounded; pre-expanded graphite (e) dry blended, and (f) pre-compounded. The inserts show higher magnifications and the exterior wall is on the right hand side.

Figure 10. Fitting the Halpin-Tsai model to Young's moduli data of injection molded composites. The lines generated for perfect platelet alignment and completely random platelet orientations are indistinguishable in this plot. 
Table 1: Physical properties of graphite

\begin{tabular}{lccc}
\hline Graphite type & $\mathbf{D}_{\mathbf{5 0}}, \boldsymbol{\mu \mathbf { m }}$ & Surface area, $\mathbf{~ m}^{\mathbf{2}} / \mathbf{g}$ & Density, $\mathbf{g} / \mathbf{c m}^{\mathbf{3}}$ \\
\hline Zimbabwean graphite & 112 & 4.0 & 2.34 \\
Expandable ES 250 B5 & 381 & 2.4 & 2.08 \\
Expanded ES 250 B5 & - & 16.3 & 0.66 \\
Expandable ES170 300A & 521 & 2.09 & 2.23 \\
\hline
\end{tabular}

Table 2. Processing conditions

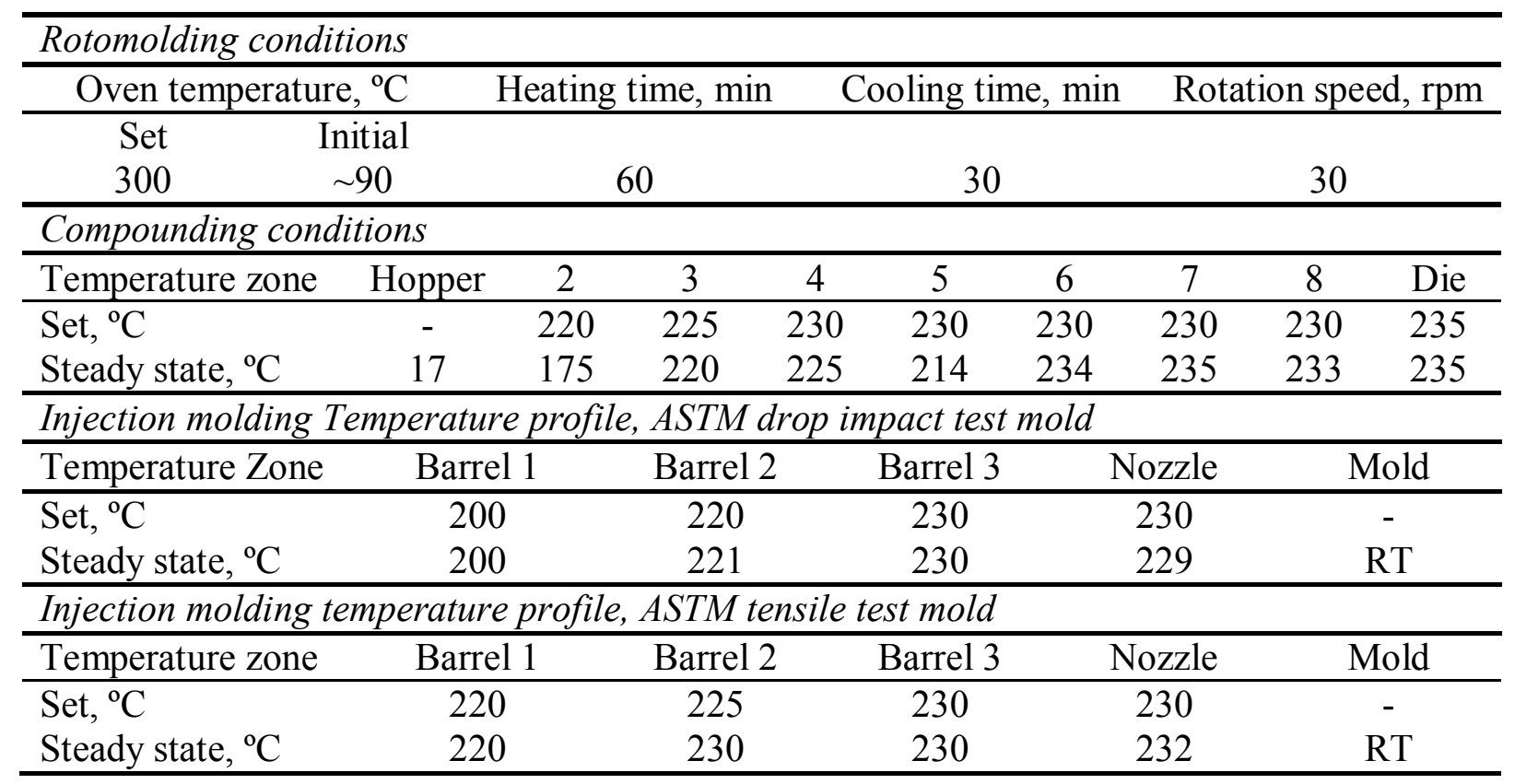


Table 3. Effect of graphite type and content as well as processing method on the Young's modulus (MPa) of LLDPE /graphite composites

\begin{tabular}{|c|c|c|c|c|c|c|c|c|c|}
\hline \multirow{2}{*}{ Processing metho } & & \multicolumn{8}{|c|}{ Graphite content, wt.\% } \\
\hline & & 0 & 2 & 5 & 8 & 10 & 15 & 20 & 25 \\
\hline Injection molding & Neat LLDPE & $189 \pm 23$ & & & & & & & \\
\hline Rotomolding & Neat LLDPE & $204 \pm 56$ & & & & & & & \\
\hline \multicolumn{10}{|c|}{ Zimbabwean graphite } \\
\hline Injection molding & & & & $216 \pm 8$ & & $233 \pm 11$ & $265 \pm 4$ & $310 \pm 3$ & $320 \pm 13$ \\
\hline \multirow[t]{2}{*}{ Rotomolding } & Dry blend & & & $203 \pm 37$ & & $226 \pm 13$ & $225 \pm 22$ & $204 \pm 19$ & \\
\hline & Compounded & & & $211 \pm 54$ & & $231 \pm 23$ & $189 \pm 39$ & $179 \pm 42$ & $111 \pm 12$ \\
\hline \multicolumn{10}{|c|}{ Expandable graphite } \\
\hline Injection molding & & & & $207 \pm 20$ & & $226 \pm 5$ & $249 \pm 28$ & $282 \pm 38$ & \\
\hline \multirow[t]{2}{*}{ Rotomolding } & Dry blend & & & $186 \pm 17$ & & $145 \pm 15$ & $141 \pm 20$ & $162 \pm 68$ & \\
\hline & Compounded & & & $129 \pm 22$ & & $123 \pm 9$ & $104 \pm 27$ & $81 \pm 9$ & \\
\hline \multicolumn{10}{|c|}{ Expanded graphite } \\
\hline \multirow{3}{*}{$\begin{array}{l}\text { Injection molding } \\
\text { Rotomolding }\end{array}$} & & & $196 \pm 21$ & $239 \pm 16$ & $235 \pm 9$ & $257 \pm 20$ & & & \\
\hline & Dry blend & & & $210 \pm 22$ & & $178 \pm 14$ & $182 \pm 24$ & $158 \pm 8$ & \\
\hline & Compounded & & $186 \pm 36$ & $188 \pm 23$ & $149 \pm 52$ & $101 \pm 26$ & & & \\
\hline
\end{tabular}


Table 4. Effect of graphite type and content as well as processing method on the yield strength (MPa) of LLDPE /graphite composites

\begin{tabular}{|c|c|c|c|c|c|c|c|c|c|}
\hline \multirow[b]{2}{*}{ Processing method } & & \multicolumn{8}{|c|}{ Graphite content, wt.\% } \\
\hline & & 0 & 2 & 5 & 8 & 10 & 15 & 20 & 25 \\
\hline Injection molding & Neat LLDPE & $16.5 \pm 0.2$ & & & & & & & \\
\hline Rotomolding & Neat LLDPE & $21.5 \pm 0.4$ & & & & & & & \\
\hline \multicolumn{10}{|c|}{ Zimbabwean graphite } \\
\hline Injection molding & & & & $18.2 \pm 0.1$ & & $18.4 \pm 0.6$ & $19.4 \pm 0.3$ & $20.8 \pm 0.3$ & $20.6 \pm 0.1$ \\
\hline \multirow[t]{2}{*}{ Rotomolding } & Dry blend & & & $19.4 \pm 0.4$ & & $17.4 \pm 0.9$ & $15.9 \pm 1.4$ & $13.9 \pm 1.7$ & \\
\hline & Compounded & & & $19.6 \pm 1.0$ & & $18.1 \pm 1.4$ & $14.8 \pm 1.8$ & $12.3 \pm 0.6$ & $6.0 \pm 2.3$ \\
\hline \multicolumn{10}{|c|}{ Expandable graphite } \\
\hline Injection molding & & & & $17.6 \pm 0.4$ & & $17.5 \pm 0.4$ & $17.9 \pm 0.4$ & $18.5 \pm 0.9$ & \\
\hline \multirow[t]{2}{*}{ Rotomolding } & Dry blend & & & $16.9 \pm 0.4$ & & $12.1 \pm 0.4$ & $9.7 \pm 0.7$ & $9.2 \pm 1.1$ & \\
\hline & Compounded & & & $13.6 \pm 0.7$ & & $10.6 \pm 0.8$ & $4.3 \pm 0.5$ & $0.8 \pm 0.4$ & \\
\hline \multicolumn{10}{|c|}{ Expanded graphite } \\
\hline \multirow{3}{*}{$\begin{array}{l}\text { Injection molding } \\
\text { Rotomolding }\end{array}$} & & & $15.9 \pm 0.4$ & $17.1 \pm 0.4$ & $17.2 \pm 0.6$ & $17.3 \pm 0.4$ & & & \\
\hline & Dry blend & & & $18.3 \pm 0.3$ & & $15.3 \pm 0.4$ & $12.7 \pm 0.3$ & $11.2 \pm 1.0$ & \\
\hline & Compounded & & $18.8 \pm 0.4$ & $18.1 \pm 0.6$ & $11.5 \pm 0.2$ & $7.9 \pm 0.8$ & & & \\
\hline
\end{tabular}


Table 5. Effect of graphite type and content as well as processing method on the elongation-at-break (\%) of LLDPE /graphite composites

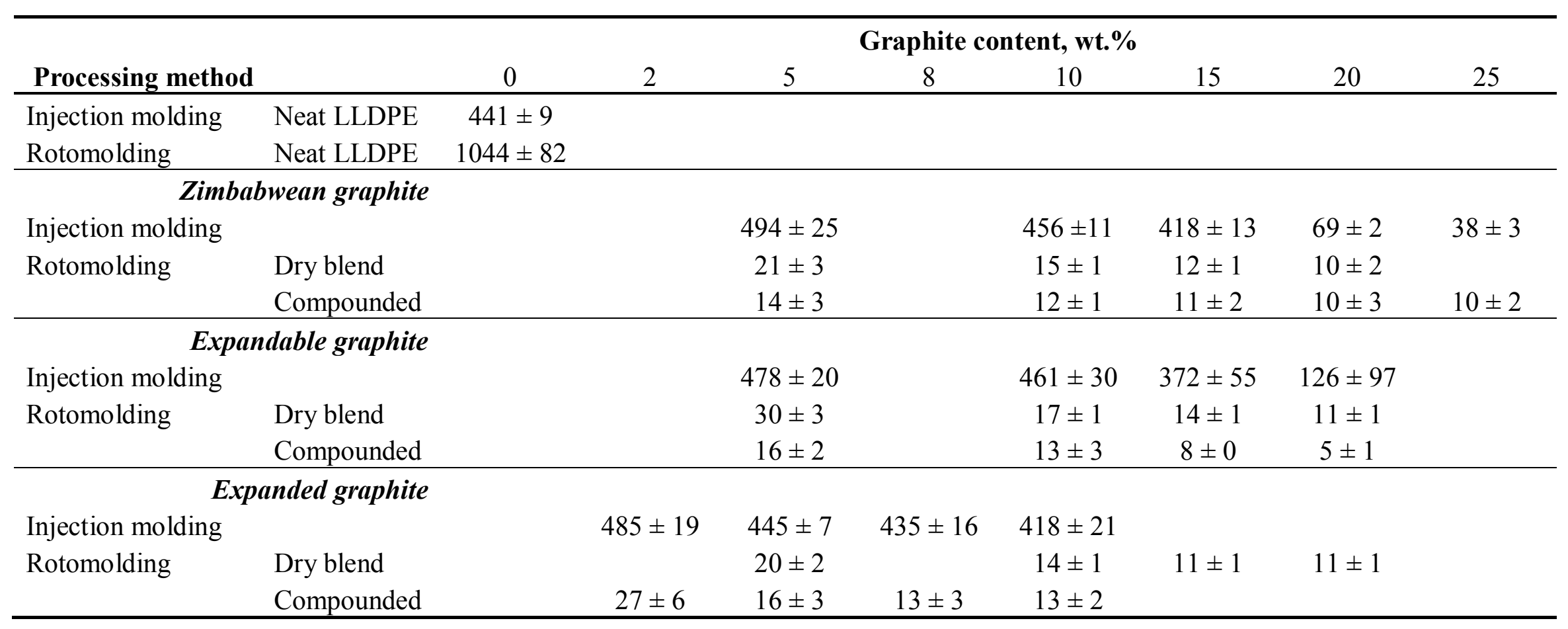


Table 6. Drop weight (Gardner) Impact Strength of LLDPE/graphite composites

\begin{tabular}{|c|c|c|c|c|c|c|c|c|c|}
\hline \multirow{2}{*}{\multicolumn{2}{|c|}{ Processing method }} & \multicolumn{8}{|c|}{ Graphite content, wt. \% } \\
\hline & & 0 & 2 & 5 & 8 & 10 & 15 & 20 & 25 \\
\hline \multirow{2}{*}{$\begin{array}{l}\text { Injection molding } \\
\text { Rotomolding }\end{array}$} & Neat LLDPE & 14.16 & & & & & & & \\
\hline & Neat LLDPE & 9.19 & & & & & & & \\
\hline \multicolumn{10}{|c|}{ Zimbabwean graphite } \\
\hline \multicolumn{2}{|c|}{ Injection molding } & & & 8.72 & & 9.69 & 8.67 & 7.63 & 6.19 \\
\hline \multirow[t]{2}{*}{ Rotomolding } & Dry blend & & & 0.91 & & 0.77 & 0.66 & & \\
\hline & Compounded & & & 0.88 & & 0.58 & 0.52 & 0.55 & 0.75 \\
\hline \multicolumn{10}{|c|}{ Expandable graphite } \\
\hline \multicolumn{2}{|c|}{ Injection molding } & & & 9.57 & & 7.54 & 7.34 & 6.38 & \\
\hline \multirow[t]{2}{*}{ Rotomolding } & Dry blend & & & 3.83 & & 2.05 & 1.16 & 1.19 & \\
\hline & Compounded & & & 1.30 & & 0.94 & 1.21 & 1.16 & \\
\hline \multicolumn{10}{|c|}{ Expanded graphite } \\
\hline \multirow{3}{*}{$\begin{array}{l}\text { Injection molding } \\
\text { Rotomolding }\end{array}$} & & & 10.59 & 9.03 & 7.58 & 6.23 & & & \\
\hline & Dry blend & & & 2.36 & & 0.99 & 0.82 & 0.72 & \\
\hline & Compounded & & 3.26 & 1.09 & 1.21 & 1.19 & & & \\
\hline
\end{tabular}


Figure 1

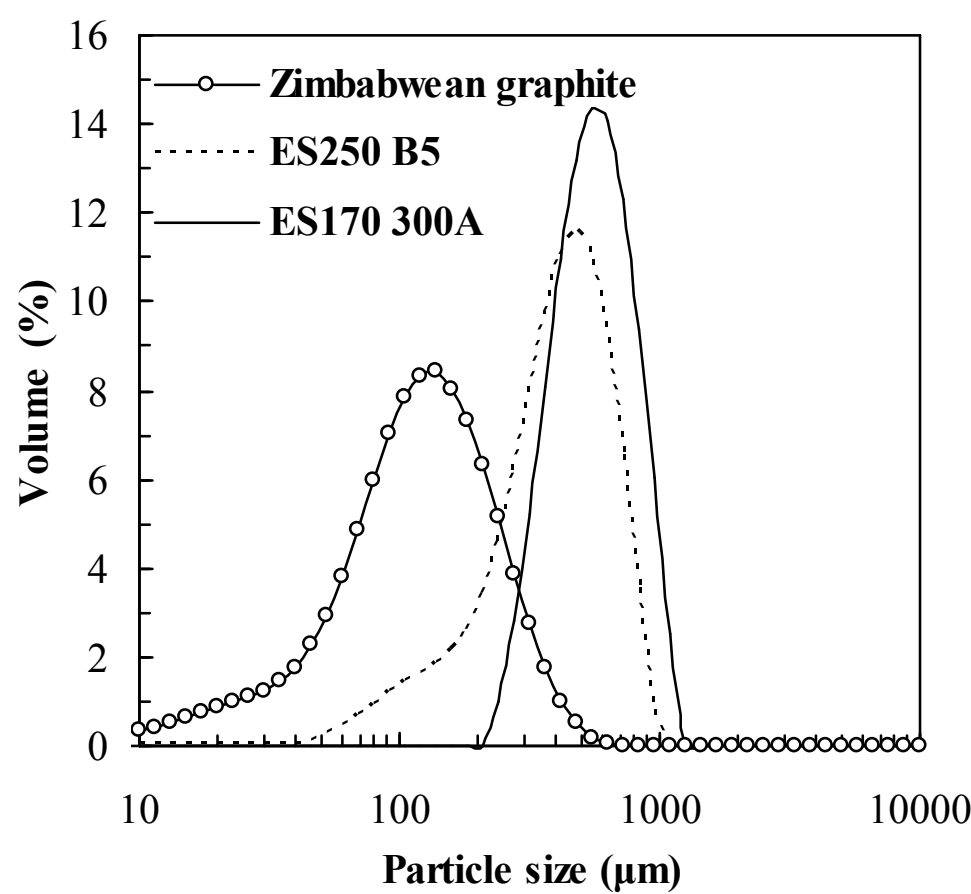

Figure 2
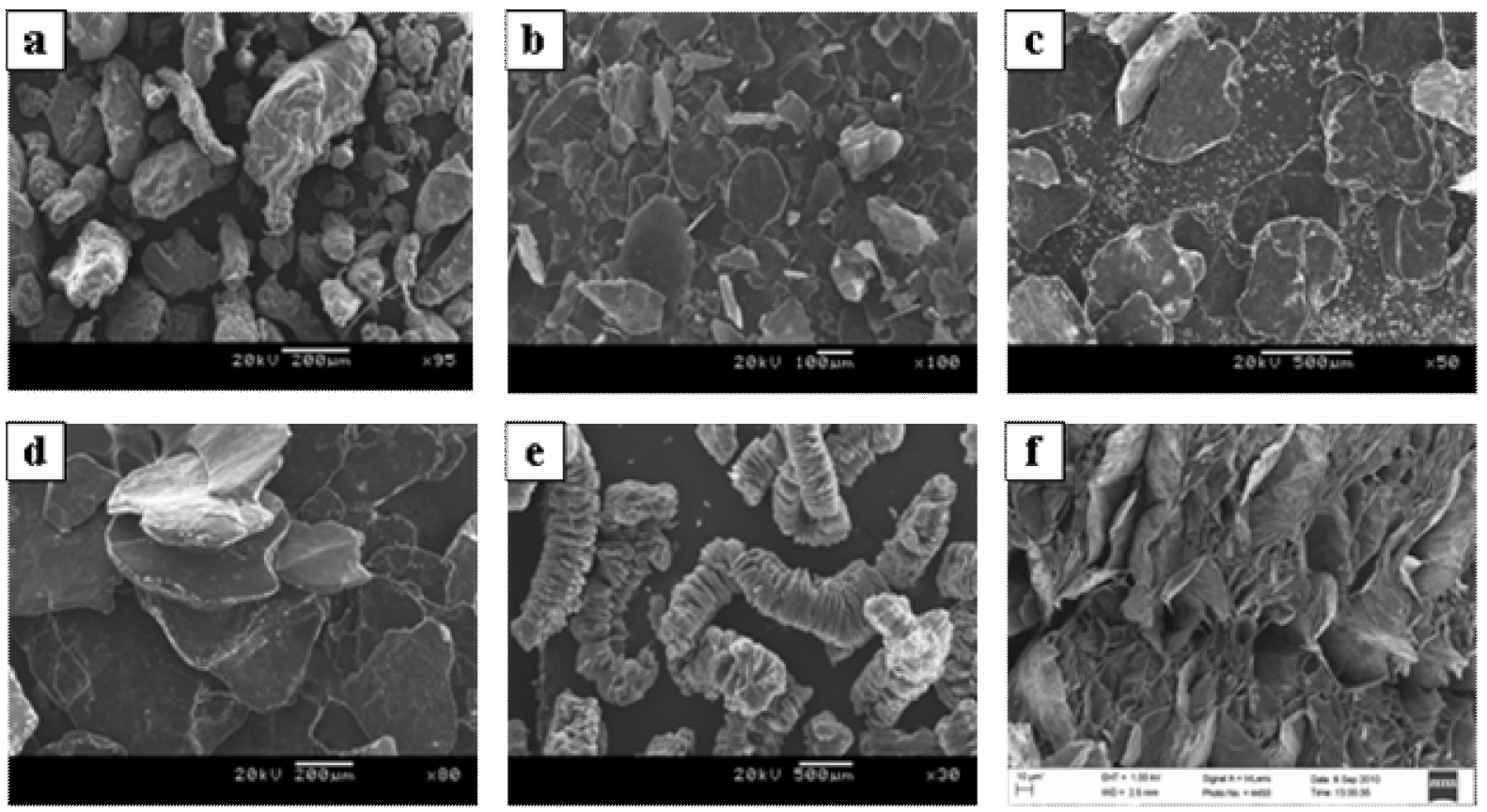
Figure 3

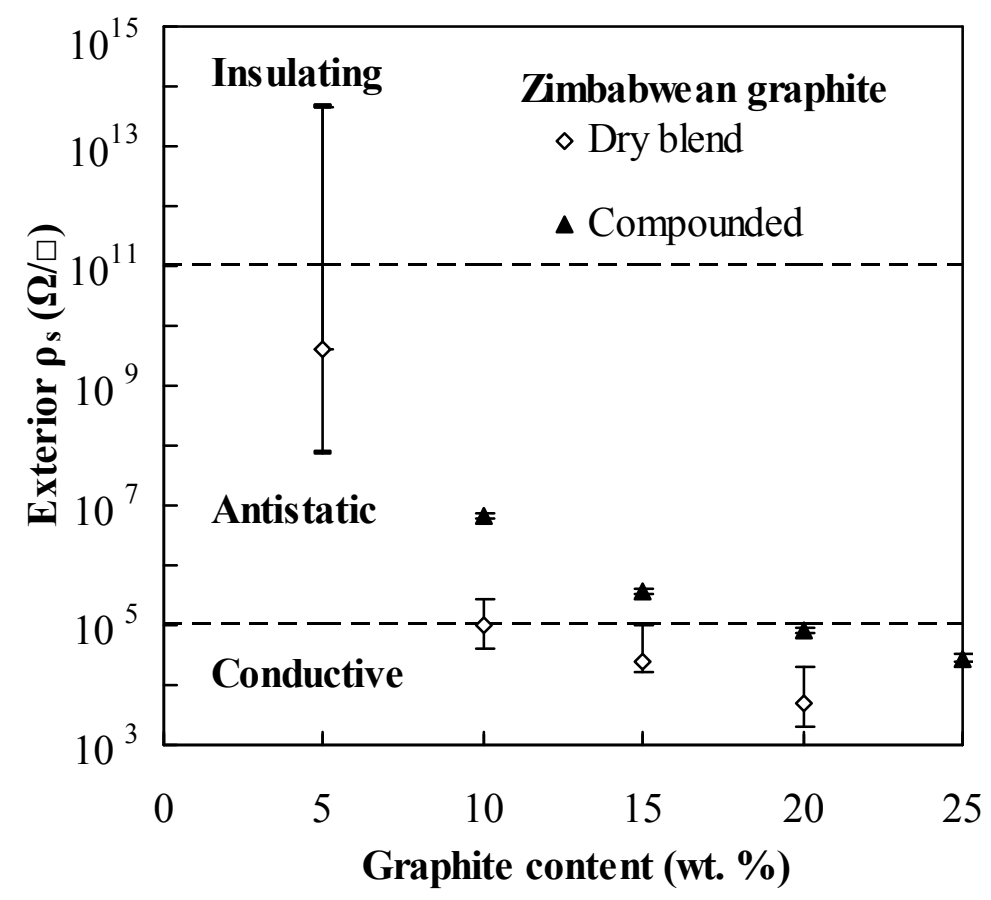

Figure 4

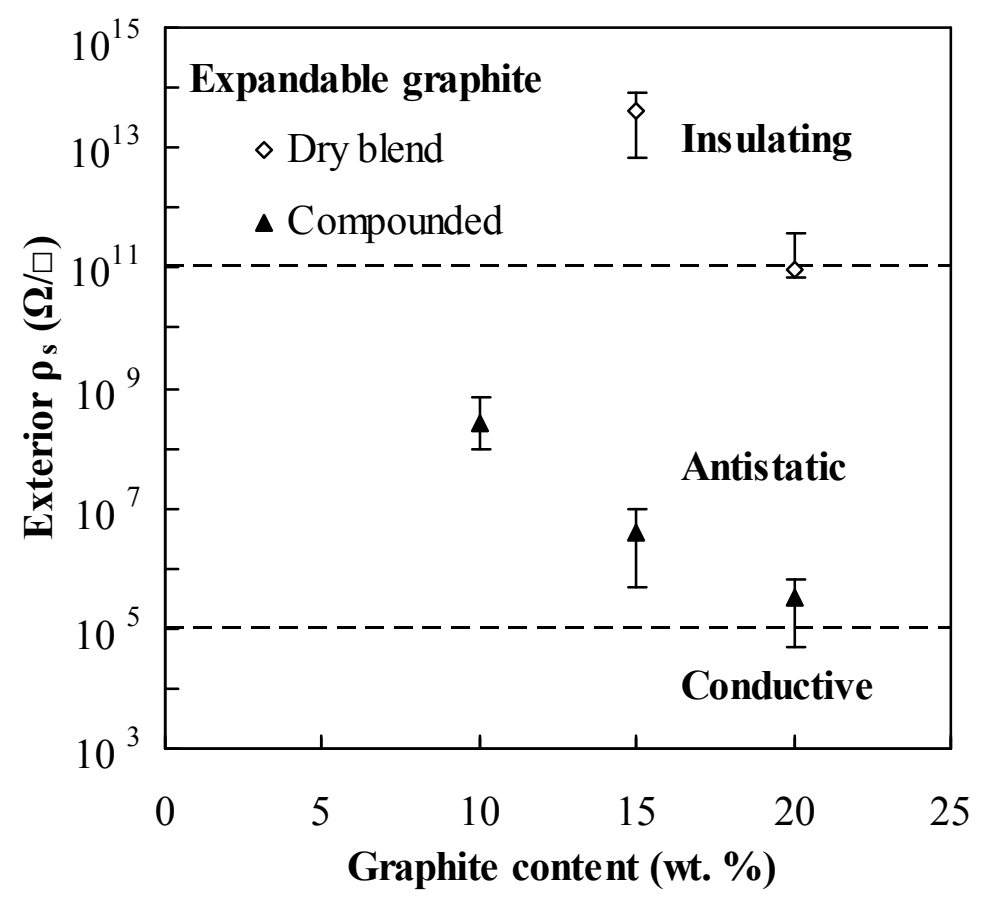


Figure 5

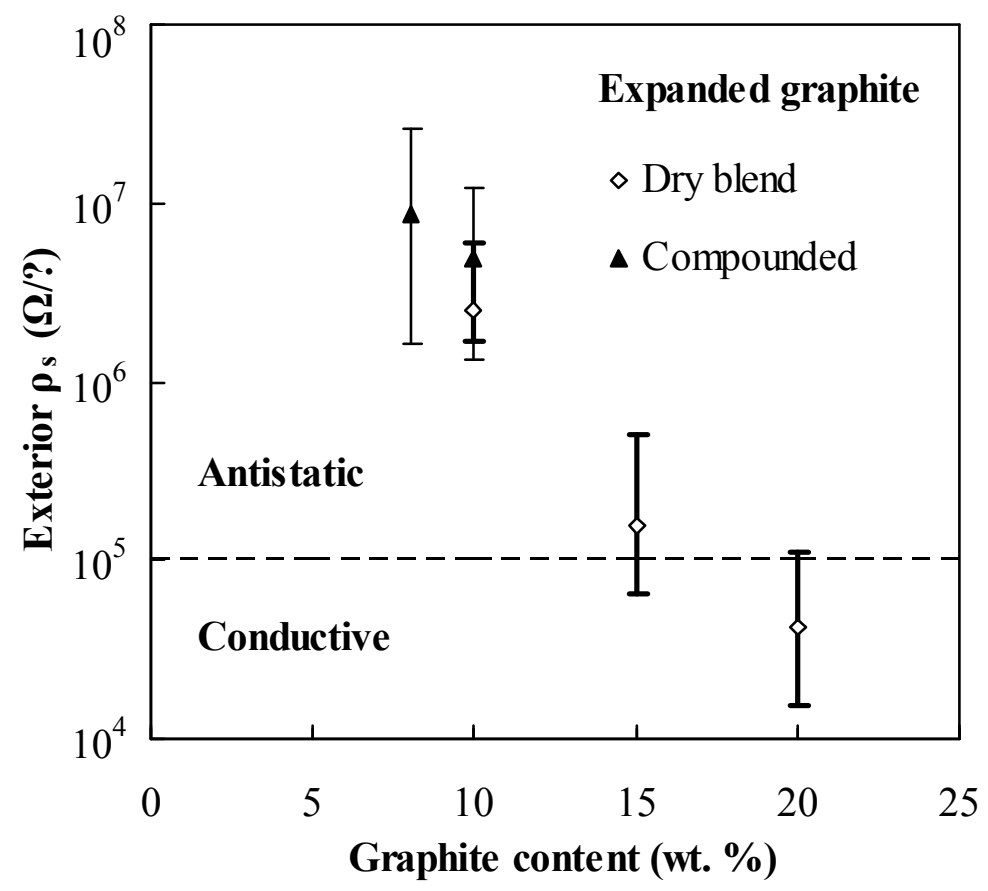

Figure 6

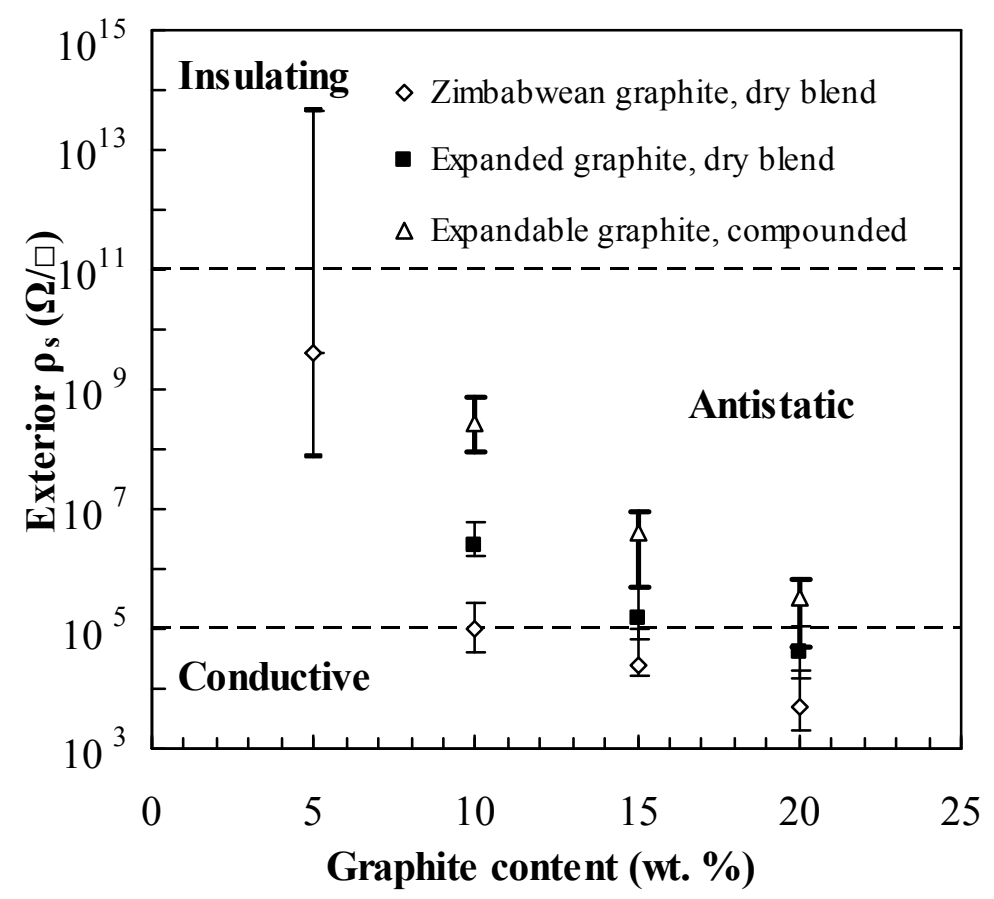


Figure 7
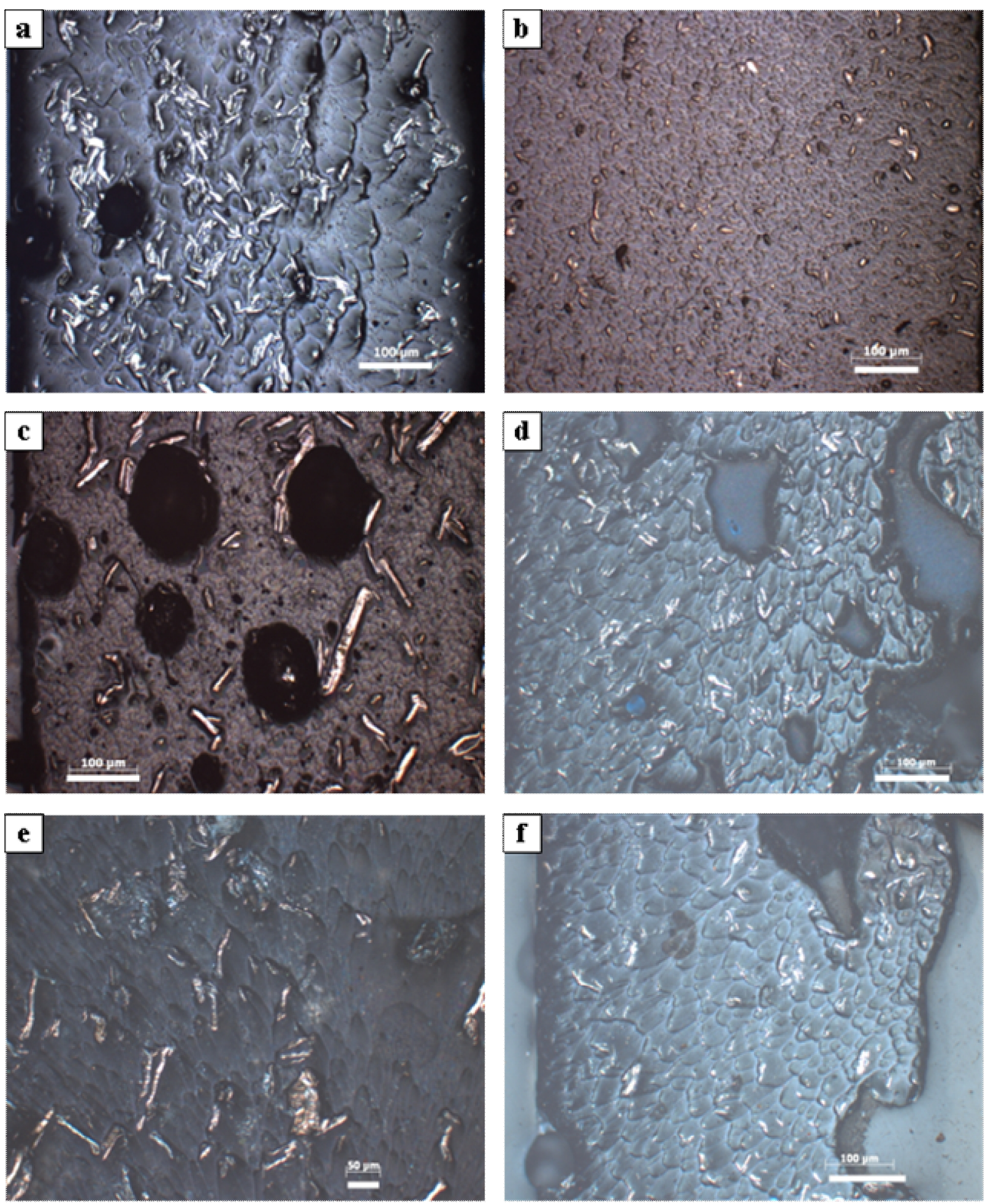
Figure 8
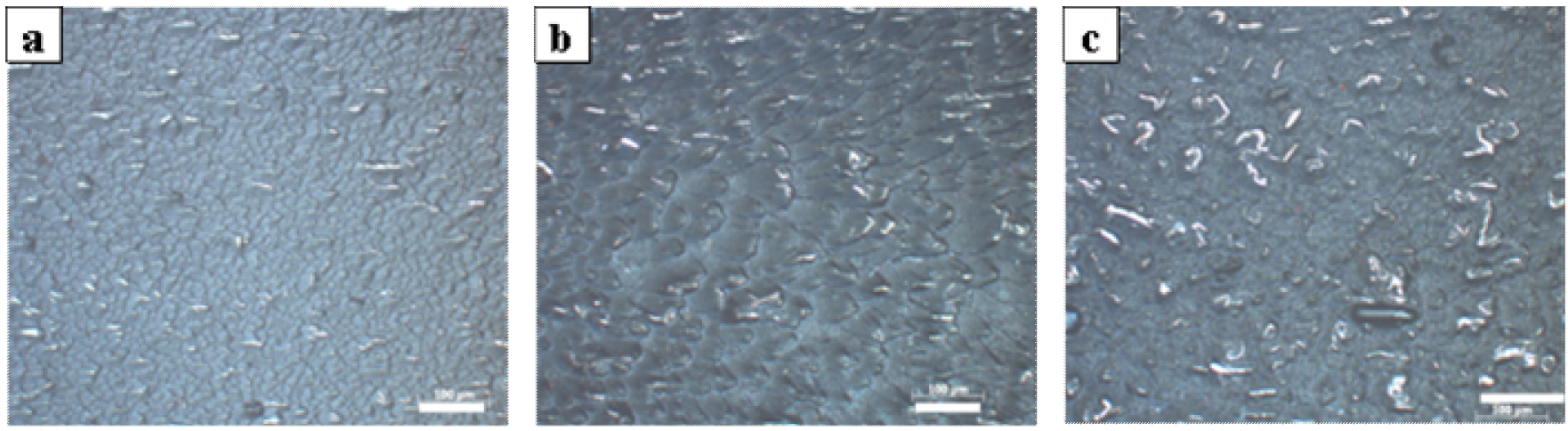
Figure 9
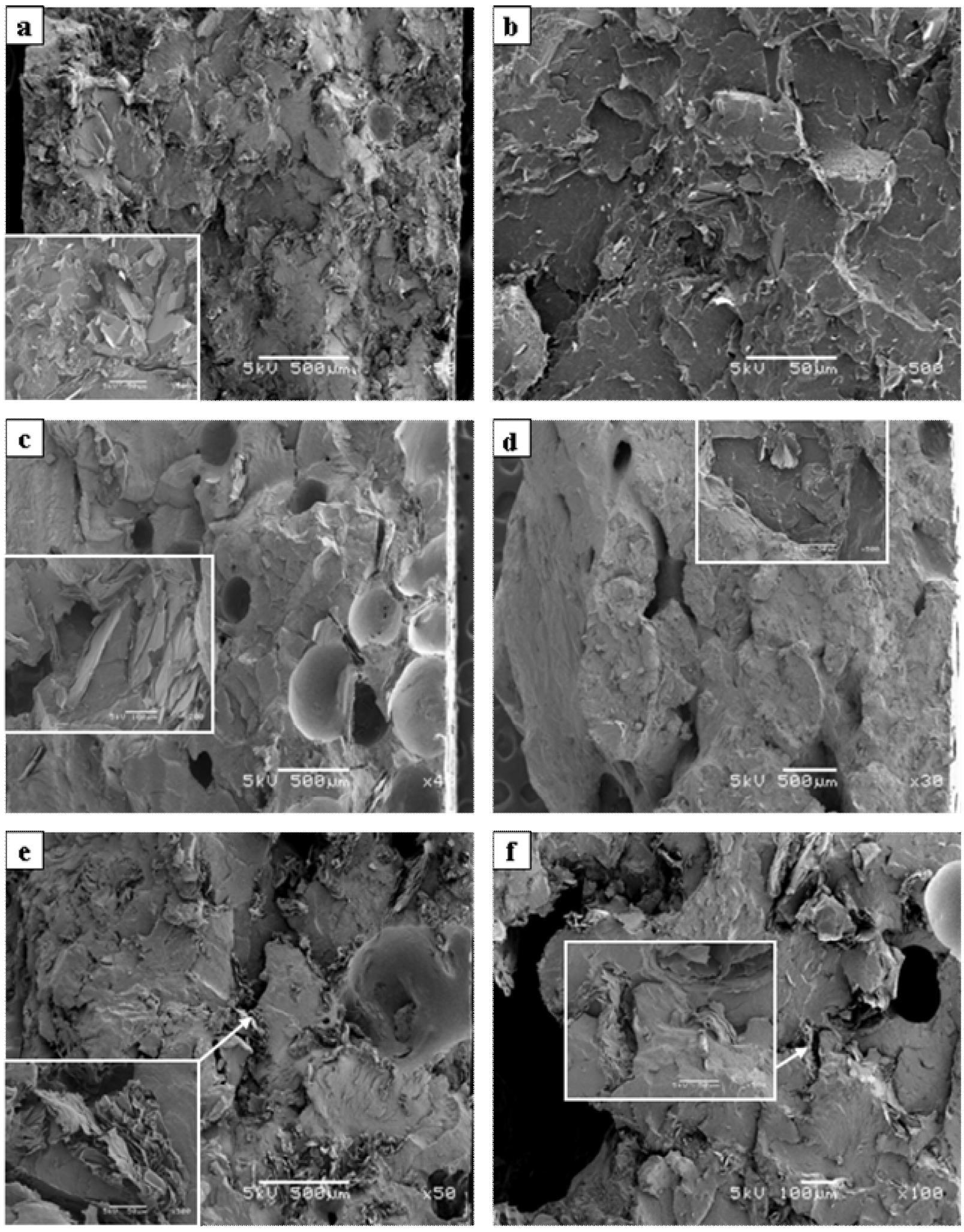
Figure 10

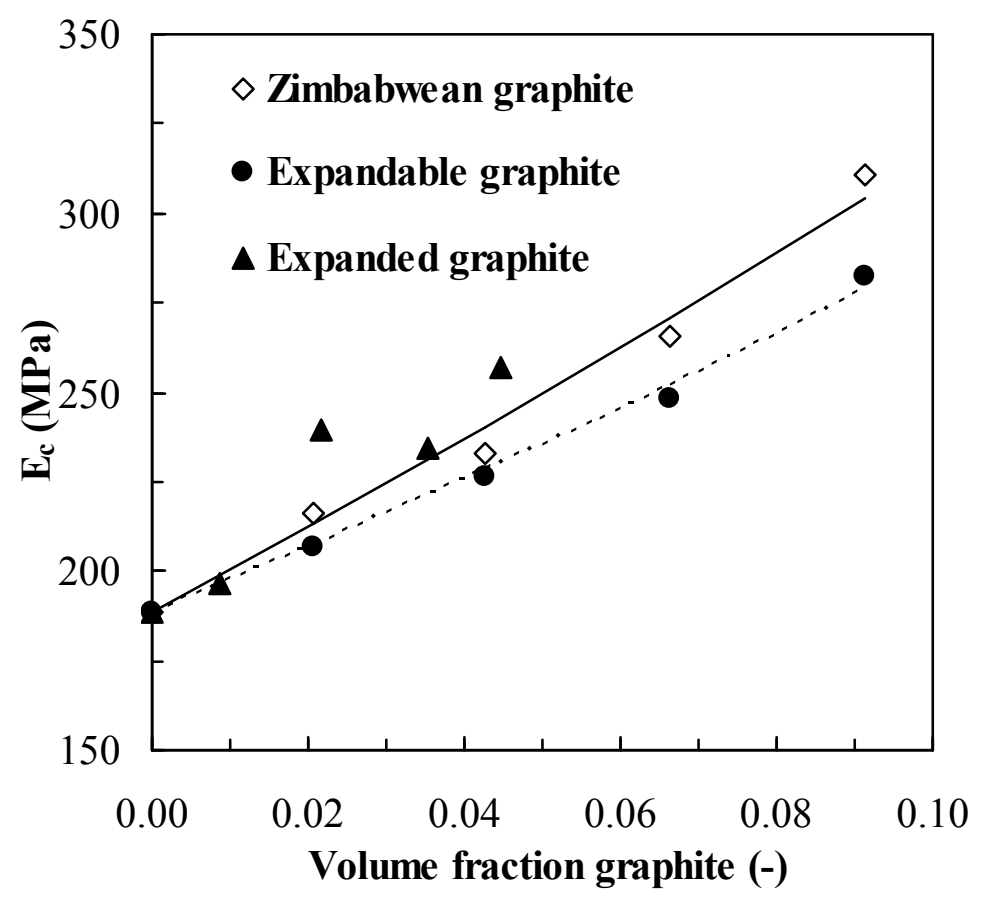

Figure 10

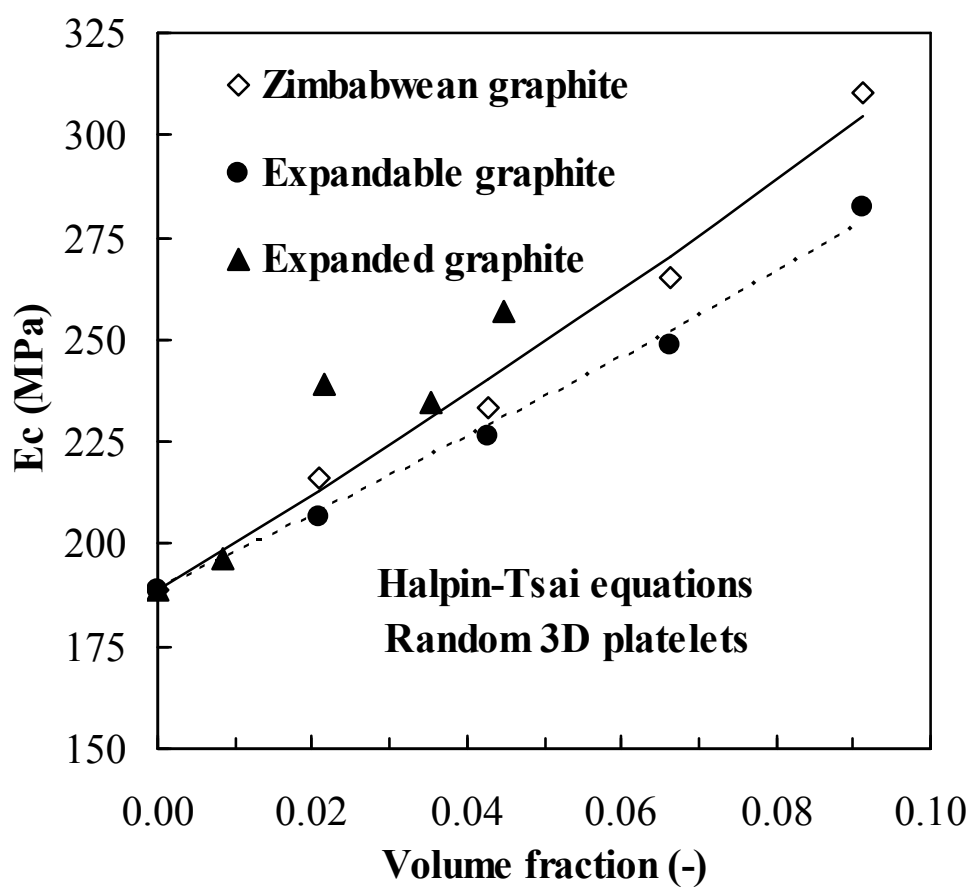

